\title{
ONTOGENY AND PHYLOGENETIC SYSTEMATICS
}

\author{
ARNOLD G. KLUGE 1 \\ 'Museum of Zoology and Department of Ecology and Evolutionary Biology, University of Michigan, Ann Arbor MI 48109
}

\begin{abstract}
Dedifferentiation, paedomorphosis, and the insertion and deletion of developmental stages make it impossible to deduce the genealogical hierarchy from only ontogenetic transformation series. Like the outgroup criterion, ontogenetic character precedence is not theory-neutral and to use it to deduce genealogy requires certain assumptions.
\end{abstract}

If scientists are going to use logically unbeatable theories about the world, they might as well give up natural science and take up religion (Lewontin, 1972: 181).

\section{Introduction}

Beatty (1982) recognized two schools of phylogenetic systematics, which he called pattern and phylogenetic cladistics (see also Platnick, 1979). According to Brady (1982: 288-89), "the pattern cladists claim that while their results are at odds with some theories, their method is without theoretical pre-judgement," and that the "method of constructing cladograms is identical with that used by the [phylogenetic] cladists." It is true that both schools emphasize synapomorphies and congruence in the discovery of sister-group relationships; however, methodological differences exist. For example, some pattern cladists advocate probability as the basis for choosing among alternative hierarchies (Patterson, 1982b: 41; Rosen, 1982: 80-81), as opposed to the parsimony rule regularly employed by the phylogenetic cladists (Farris, 1983; Kluge, 1984). An equally striking, and more widely acknowledged, methodological demarcation between the two schools concerns the criteria used to polarize character-state transformations.

Synapomorphies (putative homologies) occur at different levels of universality, and several approaches have been taken to assess those levels (Wiley, 1981: 139-158). The deductions made by phylogenetic systematists usually involve outgroup and ontogeny criteria, which are the modern equivalents of Naef's (1931) principles of systematic precedence and ontogenetic character precedence, respectively (see also Hennig, 1966: 95, 99). Pattern cladists have held the rather extreme position for the last few years that the ontogeny criterion is both necessary and sufficient for the discovery of order in nature (Patterson, 1982b: 67). Simply put, ontogeny is orderly-just classify ontogenetically (Nelson and Platnick, 1981; Rosen, 1982).

Phylogenetic cladists have tended to use both ontogenetic and outgroup criteria whenever possible, although recently a preference has been shown for outgroup analysis. For example, Brooks and Wiley (1985:10) considered "Direct observation of ontogeny does not resolve any cases of evolutionary change in ontogeny which outgroup comparisons fail to resolve, and outgroup comparisons resolve some cases which direct observation fails to resolve." Farris (1982) has also shown that the outgroup criterion is a special application of the more general parsimony rule, which he demonstrated was indispensable to phylogenetic analysis (1983).

Thus, the methods of pattern and phylogenetic cladists are not identical in all respects. Is the divergence of the two schools based on some fundamentally different world view? Beatty (1982) argued that the pattern cladists' disillusionment with evolutionary theorizing led them to seek a theory-neutral and assumption-free approach to phylogenetic inference. He supported his position by reference to how the two schools treated species, as individuals or as classes (see rejoinders by Patterson, 1982a; Platnick, 1982; and 
Brady, 1982). I believe the different views of ontogeny more clearly document the philosophical schism among phylogenetic systematists. In this context one might argue that the pattern cladists' motive rests on how the relation between pattern and processes is to be understood. I surmise that pattern cladists wish to deduce patterns from strictly empirical evidence so that the explanatory hypotheses pertaining to processes can be evaluated independently (Brady, 1982; Rosen, 1982). However, does ontogeny provide strictly empirical evidence of pattern, or is it embedded in theory about processes, and what are the consequences for understanding processes when a strictly empirical world view is assumed? The focus of my paper is the contention that the ontogeny criterion is "without theoretical prejudgement." I will conclude that its use in phylogenetic systematics is laden with theory and assumptions, and that the pattern cladists' preference has been affected by their theory-antagonistic attitude (Beatty, 1982; Brooks and Wiley, 1985).

\section{Uses of Ontogeny}

No two ontogenies are exactly alike. Just as there is variation among adults, at the individual, geographic, and species levels of examination, so is there among subadults, embryos, and eggs. The modification involves both deletions and insertions. While systematists have tended to use only adults in their search for general patterns and the underlying processes that produced those patterns, there is no compelling reason for being so exclusive (Garstang, 1922; de Beer, 1958; Bonner, 1965, 1974; Gould, 1977).

Observations of ontogeny have three basic uses in phylogenetic systematics. They may provide an assessment of homology (Wiley, 1981: 121-122), serve as an extra source of observations with which to judge historical relationships, or serve to polarize character transformations. The last forms the most prominent use in cladistics.

Literally being able to see one aspect of the phenotype transform into another during ontogeny $\left(x \rightarrow x \text { in taxon } A \text { and } x \rightarrow x^{\prime} \text { in taxon } B \text {, with } x=x^{\prime}\right)^{\prime}$ has long been recognized as a powerful basis on which to establish a claim of homology (Russell, 1916; Patterson, $1982 \mathrm{~b}$ ). Ordinarily, however, the actual transformation is not observed, and in many instances it cannot be witnessed. For example, the primary appendicular muscles of amniotes develop from undifferentiated masses of mesenchyme (termed blastema) located within the limb buds; whereas, in other vertebrates those muscles can be seen to develop from particular trunk myotomes (Smith, 1960). Similarly, a primordial mass of mesenchyme cells gives rise to the middle ear ossicles in some vertebrates (e.g., humans) and their more specific developmental origin cannot be traced (Patten, 1964). In all cases where ontogenetic character precedence is not observed, the test of homology is reduced to congruence among synapomorphies whose levels of generality have been deduced using outgroup analyses. Further, as a pretest of their homology, the degree of topographic and compositional similarity of the derived states ( $\mathrm{x}$ in taxon $\mathrm{A}$, and $x^{\prime}$ in taxon $B$, with $x=x^{\prime}$ ) must be estimated (Patterson, 1982b). That there exists some positive relationship between similarity and homology seems to be an unavoidable assumption in these procedures.

Ontogenetic transformation series may serve as a source of raw character-state data, in addition to those traditionally recorded from the adult stage. Hennig (1966) recognized this potential in his concept of semaphoront-an organism at a particular stage in ontogeny. He urged the study of comparable semaphoronts, and asserted that all semaphoront stages predict genealogy. Of course, any data collected for purposes of

\footnotetext{
1Throughout the paper, I use lower case letters for characters, superscripts for their states, and an arrow between two states denotes an observed ontogenetic transformation. A simple horizontal line signifies a hypothesized ontogenetic transformation based on topographic and compositional similarity. Upper case letters are used for taxa. An equals sign between states implies homology.
} 
phylogenetic inference, including those on semaphoronts, must be polarized in order to discover the hierarchy of synapomorphies.

Rosen (1982) exhibited even more enthusiasm for ontogenetic data than did Hennig. He pointed out that ontogenetic transformation series are necessarily more informative

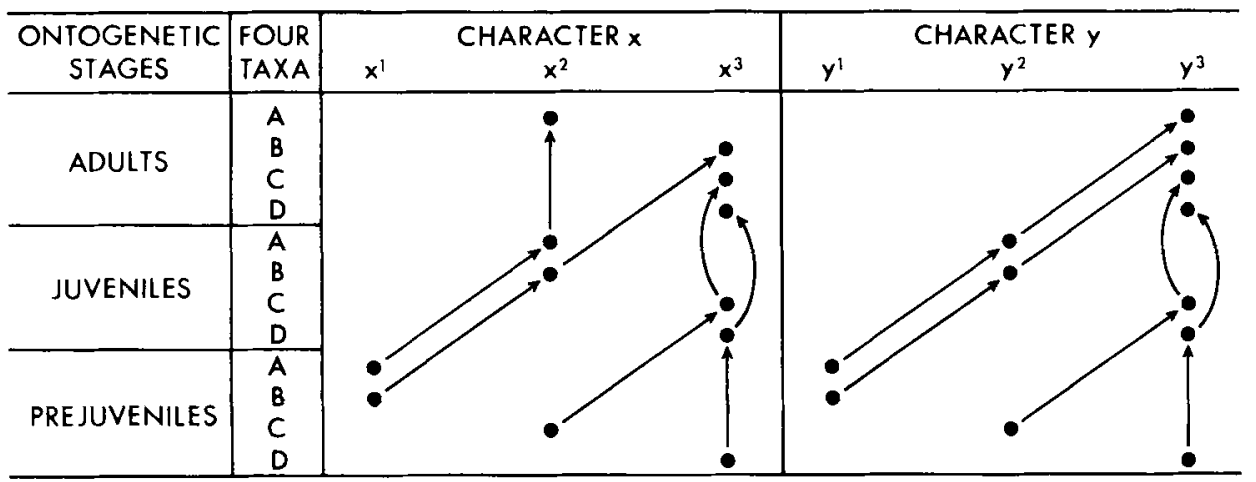

Fig. 1. The ontogenetic transformation series of two three-state characters $\left(x^{1-3}, y^{1-3}\right)$ observed in four taxa (A-D). The arrows characterize the developmental continuum between the arbitrarily chosen three ontogenetic stages, prejuvenile, juvenile, and adult (example modified after Rosen, 1982)
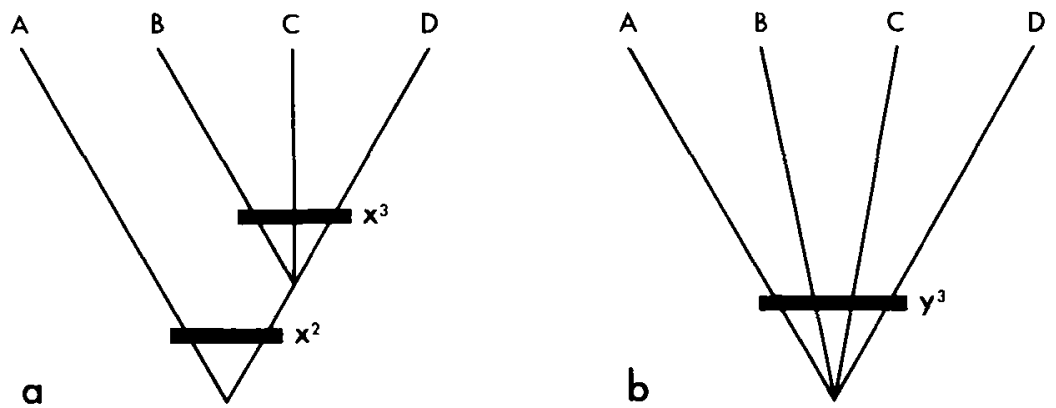

Fig. 2. Cladograms deduced from characters $\mathrm{x}$ and $\mathrm{y}$-adult states only (see Fig. 1).
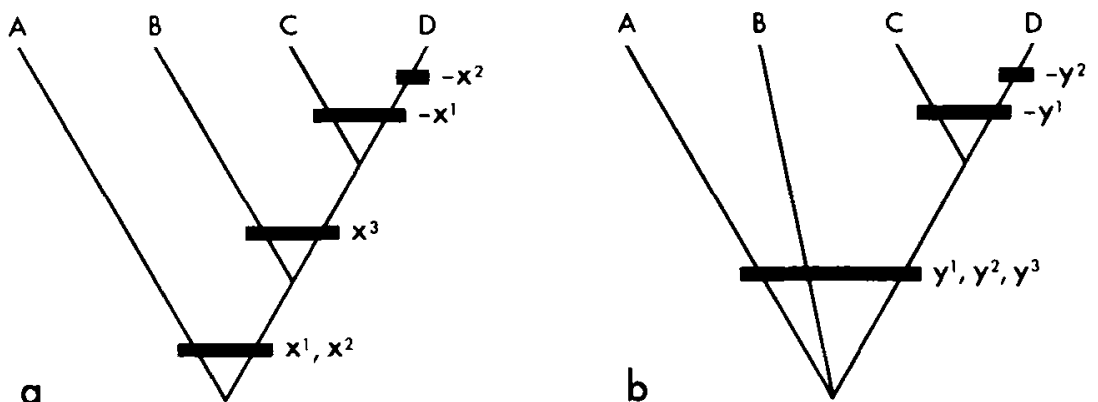

Fig. 3. Cladograms deduced from characters $x$ and $y$-all states considered (see Fig. 1). See text for necessary assumptions. 
of a hierarchic pattern than are observations on a single stage (e.g., adults alone). For that reason, he argued that the study of ontogeny should be preeminent in phylogenetic systematics (Figs. 1-3; see also Patterson, 1982b: 67). However, the particular model that Rosen proposed seems to run counter to the pattern cladists' pursuit of simplicity (Sober, 1975) because it allows the absence of something to be treated as the presence of that thing and so participate in a synapomorphy. This requires one or more assumptions. Thus, one can arrive at a cladistic hypothesis, such as Rosen's cladograms reproduced here as Figure 3, only by assuming either (1) outgroups which predict that the presence of $x^{1}$ and $x^{2}$ are primitive (not specialized insertions), (2) some form of recapitulation, i.e., any earlier states must have been present in the ancestral ontogeny (they can be lost, but not inserted), or (3) the basic information on adults (as in Fig. 2) cannot be contradicted.

Both the ontogeny criterion and Rosen's model (Figs. 1-3) assume that ontogenetic transformation series are fundamentally orderly (Nelson, 1978: 336; Patterson, 1982b), and von Baer's law is usually cited as a strict universal supporting that proposition (Gould, 1977). Von Baer's law has been variously summarized, but I believe it can be fairly stated as development is a progression from the general to the special (Russell, 1916) or in a word-differentiation $(x \rightarrow y \rightarrow z \rightarrow$ etc. $)$. The orderliness claimed for ontogeny might be taken to mean a fixed monotonic progression from the homogeneous to the heterogeneous.

Von Baer's law, as well as the ontogeny criterion, is usually associated with the following four rules which von Baer explicitly set forth in his classic 1828-1837 treatise on comparative embryology (p. 224): (1) The general features of one of the large groups of animals [ = general types; see explanation below] appear earlier in development than the special features. (2) The less general features develop from the more general, and so on, until finally the most specialized appears. (3) The embryo of a general type of animal, instead of retracing the forms of lower members of the group, diverges more and more from them. (4) Fundamentally, the embryo of a higher animal resembles only the embryo of the lower species, never its adult form. ${ }^{2}$ Von Baer's second rule seems to be a restatement of the first, which $I$ interpret to be the real basis for the law usually attributed to him. The $3 \mathrm{rd}$ and 4 th rules are explicit refutations of the MeckelSerres law, which was later reformulated by Haeckel $(1866,1874)$ as the biogenetic law - ontogeny recapitulates phylogeny.

There are three aspects of von Baer's research that require emphasis, and which I believe affect the application of his law to all levels of differentiation, as well as its interpretation as a strict universal. Firstly, von Baer recognized only three processes of differentiation - primary or germ layer formation, histological differentiation within those layers, and the morphological differentiation of primitive organs. He does not appear to have extrapolated the concept of differentiation to the level of specialization at which most cladists recognize novelties. Secondly, von Baer was an Aristotelian essentialist and, thus, his statements were about eternal, immutable patterns - they cannot possibly be about phylogeny (D. Hull, pers. comm.). Specifically, von Baer's rules relate to differentiation within the limits of each of the four distinct general types of organisms that he recognized - the radiate, longitudinal, molluscan, and vertebrate. To von Baer the types were independent of one another; differentiation followed a different course in each (e.g., the vertebrate embryo showed at no time any agreement in total organization with any invertebrate). Lastly, the claim that differentiation never reverses itself $\left(x \rightarrow y \rightarrow x^{\prime}\right.$, with $\mathrm{x}=\mathrm{x}^{\prime}$ ) is a hypothesis, and its assumptions and generality warrant critical examination.

Other generalizations or implied universals related to the ontogeny criterion include

${ }^{2}$ Von Baer's $1828-1837$ paper is in German, and all English translations of his rules vary somewhat. 
those of Spencer (1864) and Nelson (1978). Recently, Lovtrup (1978: 352) claimed Spencer's formulation was based on von Baer's law, and he restated it in the form of a theorem: "in the course of their ontogeny the members of a set of twin taxa follow the same course of recapitulation up to the stage of their divergence into separate taxa. "3 Interpreted in the philosophy of pheneticists (and perhaps pattern cladists; see below) this might be taken to mean that the pattern of more inclusive and less inclusive sets of taxa can be deduced from the congruence of their ontogenetic transformations (Danser, 1950; Patterson, 1982b; Rosen, 1982). However, as Kopaska-Merkel and Haack (1982: 95; see also Rensch, 1960) have pointed out, the theorem is of little practical value in phylogenetic inference because "subsequent evolution [non-terminal deletions and insertions] in one or both sister taxa may obscure ontogenetic evidence of the historical (genealogical) divergence." The disturbing effects that nonterminal deletions and insertions have on the parallel between ontogeny and phylogeny have been so well-studied since the time of Darwin that I see little reason to devote more space to the subject in this essay. Plant and animal examples abound (de Beer, 1958; Gould, 1977; Holmes, 1944; Rieppel, 1979; Stevens, 1980).

Nelson (1978: 327) stated his law as "given an ontogenetic character transformation from a state observed to be more general to a state observed to be less general, the more general state is primitive, the less general derived." This formulation was said to be a restatement of the biogenetic law ${ }^{4}$ and, thus, attributable to Haeckel $(1866,1874)$; however, its content has much in common with von Baer's law (Stevens, 1980). Regardless of the historical endorsement, a special problem arises when Nelson's law is put into practice in phylogenetic systematics because the relationship between "general" and "primitive" has been presented in two different ways. According to Nelson (1978: 339), "Observation determines that different characters sometimes have different generality. Given characters of different generality, the inference is that the more general character is primitive in an evolutionary sense, and the less general character is advanced. What do I mean by different generality? ... Different ontogenetic generality: the occurrence of character $\mathbf{x}$ (more general) in species A and B, in contrast to the occurrence of character y (less general) only in species B" (see also p. 327). Alternatively, Nelson and Platnick (1981: 37) stated that "features that appear early in development can be considered primitive relative to the modifications of those features that appear later in development." The problem can be seen in Figure 4 where commonness in Nelson's sense and ontogenetic precedence according to Nelson and Platnick (1981; or von Baer) do not necessarily lead to the same conclusion. Furthermore, it would seem that Nelson's law is a special form of ingroup analysis when commonness is used as the estimator (Estabrook, 1977; see Wiley, 1981, for a critique of common equals primitive). In those cases where the ontogenetic transformation is not actually observed, the investigator appears to be forced to use commonness in applying the ontogeny criterion, or assume that similarity is a perfect index of homology (see above).

The position of necessity and sufficiency of ontogeny that the pattern cladists have taken seems to be founded on the belief that (1) the criterion of ontogenetic precedence is falsifiable, but unfalsified empirically (thus, it is strictly law-like), (2) ontogeny is orderly, and (3) that deductions can be made from ontogeny alone that minimize the number of ad hoc hypotheses necessary to explain all of the data given in a study of sister-group relationships. In effect, pattern cladists adhere to ontogeny, and the laws

\footnotetext{
${ }^{3}$ Such an idea is an old one, and it can probably be traced to Chambers (1844; see Løvtrup, 1981). Even Darwin's (1859: 449) contention that "community in embryonic structure reveals community of descent" is clearly related to this notion.

4I have not called it the biogenetic law to avoid confusing it with recapitulation, which was rejected by Nelson (1973a). I have named the law for Gareth Nelson, rather than Crowson (1970: 187), because he more clearly stated it, and in recognition of his many contributions to phylogenetic systematics.
} 
relating to it, because it frees their searches for order in nature from assumptions about evolutionary processes and mechanisms and prior knowledge claims of phylogeny, viz., "their method is without theoretical pre-judgement" - it is fundamentally simple. It is usually pointed out that, by comparison, the devotees of the outgroup criterion necessarily must assume relationships at some higher taxonomic level (Nelson and Platnick, 1981). Also, Rosen (1982) has claimed that the outgroup method must make errors with certain ontogenetic transformations (his type VII), whereas the ontogenetic criterion does not.

\section{Falsifiability}

Nelson (1978) stated that his law was falsifiable; however, Voorzanger and van der Steen (1982) have concluded otherwise. The following review examines in some detail this difference of opinion because I believe Nelson's to be the only bold attempt to formulate the criterion of ontogenetic precedence in a synthetic form.

Nelson's general model for testing is as follows: we are given two taxa, A and B, $A$ with $x$ untransformed during ontogeny and $B$ with $x$ transforming to $y$. Thus, $x$ is more general (plesiomorphic) than $\mathrm{y}$. Next, consider two other taxa, C and D, as the source of falsification. $C$ has $y^{\prime}$ untransformed throughout its ontogeny, whereas $y^{\prime}$ transforms to $x^{\prime}$ during D's ontogeny. According to Nelson, his law would imply that $\mathbf{x}$ is more primitive than $y$ and that $y^{\prime}$ is more primitive than $x^{\prime}$, and this is a contradiction, on the assumption that $\mathrm{x}=\mathrm{x}^{\prime}$ and $\mathrm{y}=\mathrm{y}^{\prime}$. Further, according to Nelson, such contradictory observations would falsify his law, since a good law should not lead from coherent evidence to contradictory conclusions. Nelson knew of no such falsifiers, and no one has published any to my knowledge.

Voorzanger and van der Steen's first criticism concerns the ambiguous conceptualization of primitiveness and generality, since they can be interpreted in either a strict von Baerian manner (Fig. 4) or in terms of commonness. They emphasized (p. 202) that "a contradiction could arise only if, e.g., ' $x$ is more primitive than $y$ within $A B$ ' is taken to imply ' $x$ is more primitive than $y$ within any group - such as ABCD containing $\mathrm{AB}$." This, they claimed, forces one to accept primitive (general) in an absolute sense, but at that level of universality $(A, B, C, D), x$ is as general as $y$, and so the law becomes inapplicable (Fig. 5). What this conclusion then suggests is that

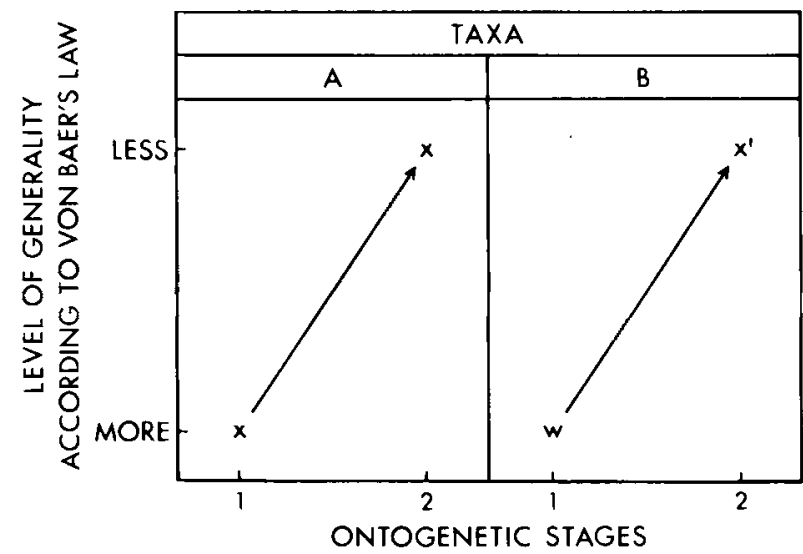

Fig. 4. Von Baer's law of ontogenetic precedence applied to two taxa, A and B. Assuming $x=x^{\prime}$, state $w$ is taken to be more general than $x$. However, state $x$ is more general than $w$ if commonness is used as the estimator instead of ontogenetic precedence. 


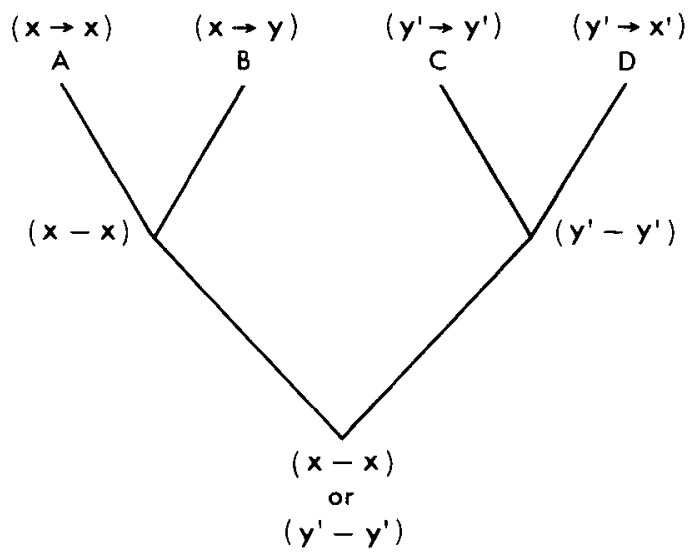

Fig. 5. The falsifiability of Nelson's law (1978) in relative terms (see text for further explanation).

falsification in terms of an ontogenetic example is impossible.

Voorzanger and van der Steen's second criticism of Nelson's test involves general being treated as a relative concept (Table 1). Assuming Nelson's model of four taxa, $A-D$, with $x-x, x-y, y-y^{\prime}$ and $y^{\prime}-x^{\prime}$ ontogenetic transformations, respectively (with $x=x^{\prime}$ and $\left.y=y^{\prime}\right)$, consider additional taxa and ontogenetic histories, $E(x-x)$ and $F$ $(\mathrm{x}-\mathrm{x})$. If $\mathrm{A}, \mathrm{B}, \mathrm{E}$, and $\mathrm{F}$ are studied first, then $\mathrm{x}$ is more general (=common). If $\mathrm{C}$ and $\mathrm{D}$ are studied next, then $\mathrm{y}$ is more general, and these conclusions of generality are contradictory and one concludes the law is falsified. But consider further the alternative outcome of a second test, where the data are exactly the same but only the study collection is partitioned differently (Table 1). Here $\mathrm{x}$ is the more general state in both sets of taxa $((A, B, C, F)(D, E))$, and the law is not falsified. Voorzanger and van der Steen were of the opinion that such opposite conclusions are not sensible, since the outcome of the test is affected by an arbitrary factor, like partitioning of the study collection, and they stated that Nelson's model for falsification is unconvincing without other considerations.

Voorzanger and van der Steen's third objection to Nelson's approach is that it does not allow the possibility to distinguish between rival hypotheses (see also Brady, 1979: 602). Ontogenetic data alone are inadequate to establish the validity of the law. I agree with their opinion that if the consequent clause of the law is to be tested it will have to come from phylogenetic hypotheses, not more ontogenetic data. Thus, I conclude that Nelson's law, while containing some empiric content, is not falsifiable in its present form. Equating generality with commonness is but part of the problem.

Table 1

Falsifiability of Nelson's Law.

\begin{tabular}{|c|c|c|c|}
\hline \multicolumn{4}{|c|}{ Generality Tests } \\
\hline \multicolumn{2}{|r|}{1} & \multicolumn{2}{|c|}{2} \\
\hline$(\mathrm{A}, \mathrm{B}, \mathrm{E}, \mathrm{F})$ & $\mathrm{x}=$ primitive & $(\mathrm{A}, \mathrm{B}, \mathrm{C}, \mathrm{F})$ & $x=$ primitive \\
\hline$(\mathrm{C}, \mathrm{D})$ & $y=$ primitive & $(\mathrm{D}, \mathrm{E})$ & $x=$ primitive \\
\hline \multicolumn{2}{|c|}{ conclusion: falsified } & \multicolumn{2}{|c|}{ conclusion: not falsified } \\
\hline
\end{tabular}




\section{Dedifferentiation}

Von Baer's law of differentiation $(\mathrm{x} \rightarrow \mathrm{y} \rightarrow \mathrm{z} \rightarrow \mathrm{etc}$.) seems to underlie whatever form the ontogeny criterion takes (including Spencer's theorem and Nelson's law), in so far as orderliness is implied. What assumptions does the law make, and how general is it? I have undertaken a search for examples of dedifferentiation $\left(x \rightarrow y \rightarrow x^{\prime}\right)$ so that I might gain insight into its generality. Moreover, I believe those examples point up an unresolvable ambiguity of these transformations which makes the law effectively useless and unsupportable, except at the most trivial level (e.g., adults do not develop into eggs). With strict differentiation in two taxa, $x \rightarrow x$ in taxon 1 , and $x \rightarrow x^{\prime}$ in taxon $2, x$ and $x^{\prime}$ are homologous. When dedifferentiation obtains there is no reason to expect congruence of actual developmental transformations, nor strictly hierarchic taxonomic patterns, because $\mathbf{x}$ and $\mathrm{x}^{\prime}$ are really not homologues, but they must be interpreted as such without making certain assumptions. Of course, one can guarantee that differentiation never reverses itself by distinguishing character states according to their precedence (e.g., $x \rightarrow y \rightarrow z-y$; the two y's look alike, but they are different because one $y$ comes after $\mathrm{x}$, while the other follows $z$ ). One might also claim, as Rosen (1982) did, that the two y's will always be distinguishable, i.e., that dedifferentiation never takes place. My review of the literature suggests that dedifferentiation exists in several kinds of organisms, and that it provides a common class of exceptions to von Baer's law (Spratt, 1964; Waddington, 1966).

Dedifferentiation is characteristic of regeneration in many plant and animal tissues, and it has been most intensively studied in salamander limbs (Butler, 1933; Grant, 1978; Steen, 1970; Thornton, 1938). Typically in salamanders, hystolysis (the dedifferentiation of stump tissues) follows the amputation of the limb. The bundles of muscle cells break down and lose their myofibrillar architecture to become single mononucleate myoblasts. The cartilage matrix dissolves as well, and the individual cells are released from it. Connective tissue is similarly altered during histolysis. The dedifferentiated cells of muscle, cartilage, and connective tissue, once having lost their specialized organelles and regained their enlarged nuclei and basophilic cytoplasm, form a blastema and enter the new growth-duplication cycle leading to regeneration of tissues.

The question of whether the blastemal cells have reverted to their totipotent embryonic state has been answered, to my satisfaction, with irradiation-tissue transplant experiments. It seems that in at least some salamanders, there are different degrees of metaplasy, viz., the transformation of one specialized tissue, through dedifferentiation, into another. For example, connective tissue can be a progenitor of all others-cartilage, perichondrium, muscle, as well as connective tissue - whereas muscle is less labile, and cartilage even less so. A graft of radioactively doubly-labeled cartilage can be shown to give rise mostly to new cartilage; however, it also produces a few perichondral cells and fibroblasts. Labeled implanted myoblasts differentiate into more cell types, including cartilage. Other examples in vertebrates include lens regeneration (Connelly, 1980; Reyer, 1977; Watanabe, 1978) and "transdifferentiation" of bladder epithelium (Cunha et al., 1980).

Dedifferentiation is also well-documented among the invertebrates, especially in Planaria and Hydra. In an extreme case of regeneration, isolated gastrodermal cells are known to dedifferentiate, lose their mucoid and secretory granules, become interstitiumlike, and regenerate all of the other cell types characteristic of a complete Hydra (Grant, 1978). Translocations in the ontogeny of other invertebrates include the lophophores in phoronids and the gut in the Bryozoa (Hyman, 1959; Siewing, 1963).

Even normal molting in acariform mites involves the regression and dedifferentiation of most body tissues. In fact, the tissues of the limbs and gnathosoma completely dedifferentiate and reform before ecdysis (Woodring, 1969). The "calyptostasis" pattern 
of development found in chiggers, velvet-mites, and water-mites, comprising some 75 families and thousands of species (Grandjean, 1957; van der Hammen, 1964, 1978, 1981), is of special interest as an exception to von Baer's law. In calyptostasis, every alternate stadium is degenerate morphologically and completely pharate, viz., never emerging from the cuticle of the previous stadium. Thus, in tracing the ontogeny of most external cuticular structures in these groups, such as legs, sensilla, and the like, a structure appears, then disappears, appears, disappears, and reappears again (B. OConner, pers. comm.). A similar pattern occurs in the nematode Hemicycliophora arenaria where the somatic musculature breaks down and reforms at each molt (Johnson et al., 1970). Dedifferentiation/redifferentiation also occurs in certain plant tissues (e.g., the epidermis; W. H. Wagner, Jr., pers. comm.; Foster, 1949: 66-67).

\section{Paedomorphosis}

It is generally acknowledged that paedomorphosis ${ }^{5}$, the phylogenetic loss of adult characters, obscures the genealogical hierarchy (Nelson, 1978; Nelson and Platnick, 1981; Stevens, 1980). However, paedomorphosis is a special problem in any specific case because evidence for it depends on some prior hypothesis of phylogeny. Advocate another set of sister-group relationships and the claim of ancestral juvenile characters being retained in the adult may no longer be required to reach the simplest explanation for the data (Fink, 1982). Still, no one seems to doubt the existence of paedomorphosis in some situations. For example, it can be observed in salamanders when it is facultative, i.e., those cases where not all individuals of a local interbreeding population metamorphose and acquire the characteristics of the terminal stages of ontogeny of their siblings and immediate relatives. The more troublesome question is how are we to discover its existence where the species is an obligate paedomorph and much of the phenotype, save the gonads, has retarded development? I agree with Eldredge and Cracraft's (1980) suggestion that one should let the outgroup criterion, multiple character congruence, and parsimony be the "arbiter" of hypotheses of paedomorphosis, for how else could something absent be discovered (Nelson, 1978: 339)?

\section{Ontogeny and Parsimony}

Nelson (1973a) claimed that assuming an earlier and more general attribute in ontogeny to be primitive perforce minimizes the number of ad hoc hypotheses (ontogenetic reversals) necessary to explain the phylogeny of a character (see also Bonde, 1976; and Nelson, 1978). Nelson coupled his point of view on ontogeny/parsimony with the thesis that assessing character-state primitiveness with ontogenetic transformation series was a direct method, and, unlike the indirect outgroup criterion, was free of the assumption of a higher level cladogram. Nelson's position seems to rest on the assumption that his law holds that the condition "in the young stages can be considered primitive" (Nelson and Platnick, 1981: 38). In effect, he must assume that paedomorphosis (see above) and ontogenetic insertions do not apply. Thus, it seems to me that both the ontogeny and outgroup criteria require certain assumptions, and that describing them as direct and indirect has nothing to do with their relative parsimony debts. Moreover, since each criterion serves to cover the assumptions of the other, one might argue that they should be used in concert whenever possible. Ultimately, multiple character congruence and parsimony will arbitrate contradictory predictions of a character's polarity.

Lundberg (1973: 327) was the first to respond to Nelson's claim and he asserted that inspecting the ontogenies of two species "cannot alone distinguish among evolutionary

${ }^{5}$ Neoteny of some authors. 
hypotheses on the basis of parsimony" (Nelson's $1973 \mathrm{~b}$ rebuttal notwithstanding). Lundberg focused on the point that to claim that the loss of something primitively present' is less parsimonious than the 'gain of something primitively absent' requires a third taxon (an outgroup to Nelson's two-taxon statement). The disagreement, and its resolution, may be more clearly understood with the simple illustrations in Figure 6. Given two taxa, $A$ and $B$, one changes in some way during its ontogeny $(x \rightarrow y$ in taxon $B)$, while the other does not $(x \rightarrow x$ in taxon $A)$. Nelson's position is that to attribute the $\mathrm{x} \rightarrow \mathrm{y}$ transformation to the common ancestor $\mathrm{C}$ of $\mathrm{A}$ and $\mathrm{B}$, as in hypothesis 2 of Figure 6 , is to admit two evolutionary transformations when only one is necessary to explain the data, as in hypothesis 1 . The extra transformation is the 'prior gain' of whatever is subsequently 'lost.' Lundberg's point was that a higher level phylogeny, involving an outgroup D (as in Fig. 7), is assumed in the notion of 'prior gain.' According to Donoghue and Maddison (1982) the ontogeny-parsimony argument can be effectively reduced to using "non-life" as the outgroup. Furthermore, it is only when the particular conditions of the outgroup (D) are specified that the relative parsimony of the alternatives can be correctly assessed, unless Nelson's law is assumed (Fig. 7). For example, if $\mathrm{D}^{2}$ with the $\mathrm{x} \rightarrow \mathrm{y}$ transformation were the ancestor of $\mathrm{C}$, hypothesis 2 would be more parsimonious, if $D^{1}$ with $x \rightarrow x$ transformation were the ancestor of $C$, hypothesis 1 would be more parsimonious, and so on. Given only two taxa, as in Figure 6, the alternative hypotheses cannot be distinguished on the basis of parsimony.

\section{The Generality of Ontogeny}

It is common knowledge that structural phenotypes, such as integument, bones, heart, and the like, have developmental histories (Patterson, 1982b). Even the behavioral phenotype appears generally to exhibit ontogeny, as does the emotional-intellectual (Piaget and Inhelder, 1969). However, it is not obvious that karyotypes, all polypeptides, individual amino acids, and genes exhibit "ontogeny." Does this mean that data drawn from those sources can have no hierarchic pattern of their own, and are irrelevant to phylogenetic systematics? I believe pattern cladists with their extreme view of ontogenetic character precedence would have to answer in the affirmative. Of course such data could be forced into a hierarchic pattern by a clustering algorithm, or fitted to a pattern deduced from characters that do exhibit ontogeny, but in either case their contribution to phylogenetic inference would not be improved. What if, for example, karyotypic change was responsible for speciation (as with polyploidy)? Wouldn't pattern cladists discount a priori the very data necessary to characterize those sister-group relationships? An equally serious dilemma concerns the many unicellular organisms (e.g., bacteria and protists)

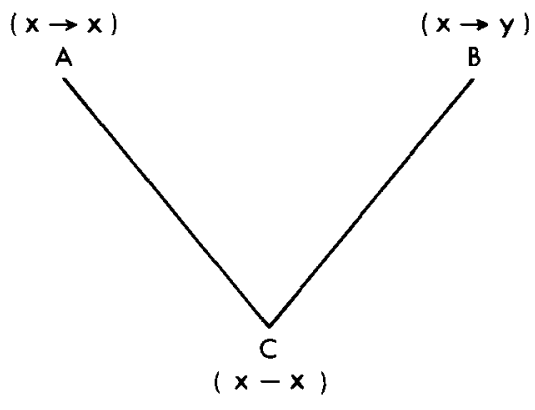

a HYPOTHESIS 1

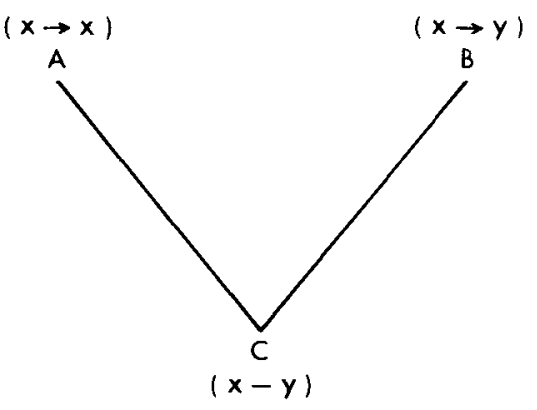

b HYPOTHESIS 2

Fig. 6. Alternative interpretations of the ontogenetic transformation in the common ancestor of two taxa, A and B. 

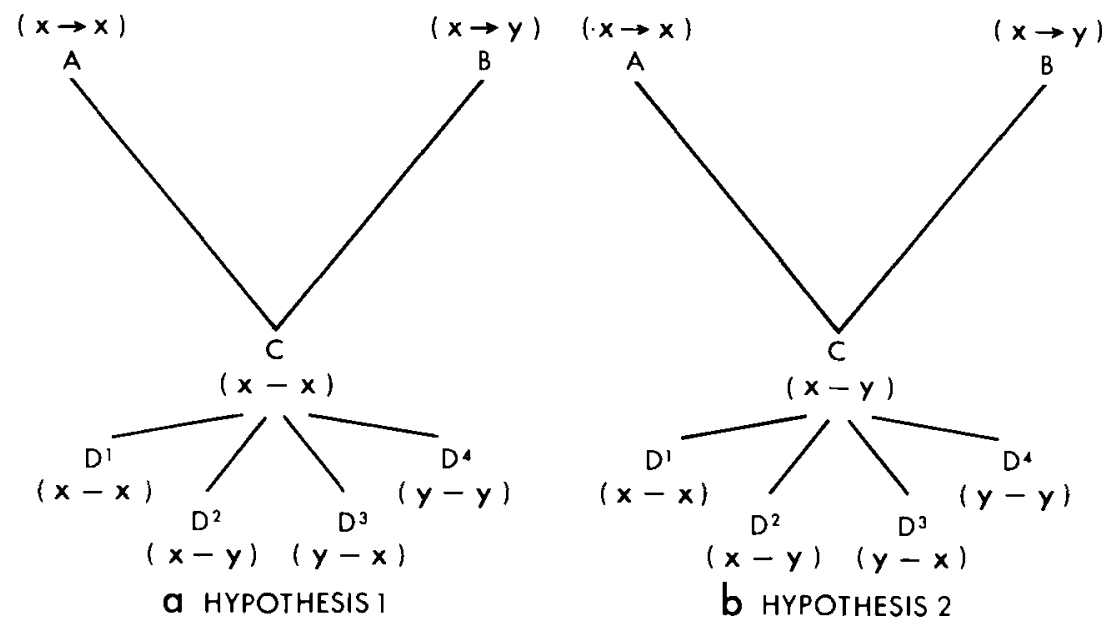

Fig. 7. Different ontogenetic transformations in the outgroup D, and their effect on choosing among alternative hypotheses on the basis of parsimony.

which may be without any ontogeny. How would the pattern cladist proceed to infer their sister-group relationships, if not by outgroup analysis?

My survey, although by no means exhaustive, suggests that many, but not all, proteins exhibit ontogeny (Uy and Wold, 1977), whereas few, if any, "genes" do. Some amino acids have what could be called ontogeny, but the purine and pyrimidine bases do not. The usual karyotypic characters employed in phylogenetic systematics also seem to be without ontogeny.

Insulin provides an excellent example (Fig. 8) of the ontogeny of a protein (Stryer, 1981). In mammals (e.g., humans, cows, etc.), the active hormone consists of two separate chains - an A chain of 21 amino-acid residues and a B chain of 30 residues which are covalently linked by two disulfide bonds. Proinsulin has no hormonal activity in these mammals, but it is the direct precursor of the hormone insulin. Proinsulin is a single polypeptide, which consists of the $\mathrm{A}$ and $\mathrm{B}$ chains covalently linked by an additional sequence of about 30 amino acid residues, the $C$ chain. Further, recent studies have found preproinsulin, a polypeptide containing the $\mathrm{A}, \mathrm{B}$, and $\mathrm{C}$ chains plus an

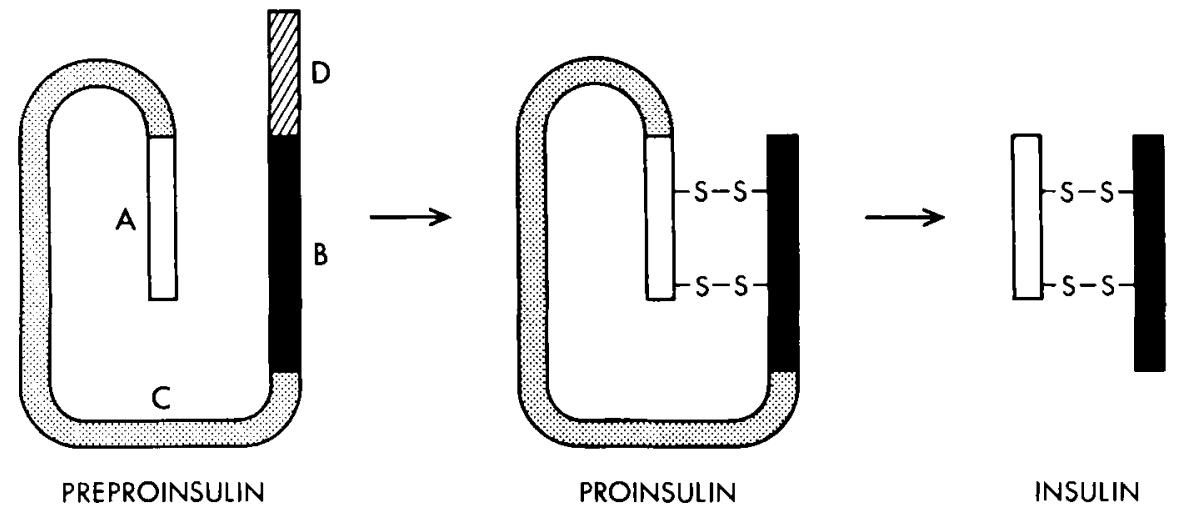

Fig. 8. The ontogeny of insulin (modified after Stryer, 1981). A. The A chain. B. The B chain. C. The connecting peptide chain. D. The amino-terminal sequence, -s-s- are disulfide links. 
amino-terminal sequence of 16 residues which is not present in proinsulin. This aminoterminal sequence is thought to channel the preproinsulin molecule to the endoplasmic reticulum, where proinsulin is formed from it by cleavage of the 16 amino acid terminal peptide. Proteolysis of the connecting $C$ peptide chain, to form the separate $A$ and $B$ chains of mature insulin, takes place in the storage granules of the Golgi apparatus. I interpret the enzymatic conversion of preproinsulin to insulin to be an example of a molecular ontogenetic transformation; however, not all proteins have such an ontogeny.

A few of the cytosine residues in the DNA of higher eukaryotes, as well as those in some lower eukaryotes, are methylated (Ehrlich and Wang, 1981). Such methylation may be dependent on DNA synthesis and completed shortly after DNA replication, or it may be completed long after DNA synthesis. Methylation of eukaryotic DNA seems to have many functions, including regulating the transcription of certain genes, increasing the rate of mutations, and increasing the stability of sections of the double helix. Differentiation is probably one of the functions because DNA methylation is correlated with the transcription of some genes (Caplan and Ordahl, 1978; Ehrlich and Wang, 1981).

I consider only some post-translational modifications of a protein as ontogenesis, and it is important to note that some of those changes are known to be reversible. According to $U y$ and Wold (1977: 890), such changes involve noncovalent and covalent interactions "which lead to the folding of the polypeptide chain and the association of individual chains with each other," and "the transport of the protein from the site of synthesis to the site of action." However, not all post-translational modifications may be equated with ontogeny. For example, phosphorylation of some tyrosine residues is a posttranslational modification that is readily reversible, and appears to be an important mechanism for regulating protein activities. The same molecules can be alternately phosphorylated or "de-phosphorylated" depending on the metabolic state of the cell. Although DNA methylation is less labile than protein phosphorylation it, too, may be found to fluctuate within the "lifetime" of a given DNA molecule.

\section{Conclusions}

Ontogeny does not always provide unambiguous evidence of the hierarchy of genealogy. Furthermore, certain major groups of living things (prokaryotes, single-cell eukaryotes) may have no ontogeny. Must we then despair of inferring a phylogeny for these organisms? Von Baer's law does not account for dedifferentiation, and the practical value of ontogenetic transformation series in deducing the natural order is significantly affected by deleted and inserted stages. A counterargument to my claim about von Baer's law being inconsistent with dedifferentiation could take the form of the truism that 'adults don't develop into eggs' (G. Nelson, pers. comm.). However, I suggest that such a position robs von Baer's rules, and the summary law(s), of whatever empirical content they might have. Also, it must be acknowledged that deleted and inserted stages cannot be deduced with the ontogeny criterion alone. In order to detect those stages one must perform phylogenetic analysis by some other means, such as outgroup comparison, multiple character congruence, and parsimony. Further, it seems doubtful that the number of ad hoc hypotheses about character evolution can be minimized with the ontogeny criterion, without appealing to an outgroup at some level. When the generality of ontogenetic data is estimated from the commonness of the character states one is endorsing ingroup analysis and is thus accepting its underlying assumptions.

Like the outgroup criterion, ontogenetic character precedence is not theory-neutral and its use in deducing sister-group relationships requires certain assumptions. To maintain the position that von Baer's law is a universal in the strict sense and that the study of ontogeny is both necessary and sufficient to do phylogenetic systematics will only be to the detriment of our understanding the origin of diversity and how it is constrained 
by intrinsic factors. In fact, it will actually prevent discovery of phenomena such as paedomorphosis and non-linear ontogenetic sequences. Moreover, to classify only by the ontogenetic criterion is to give the impression that it really doesn't matter whether ontogeny reflects evolution and that the inference of phylogeny is not a goal. This is unacceptable to phylogenetic cladists because they are interested in discovering historical patterns and the processes that produce them.

\section{Acknowledgments}

I thank Dan Brooks, Wes Brown, Barry Chernoff, Bill and Sara Fink, Carl Gans, L. van der Hammen, Larry Heaney, David Hull, Fred Kraus, Lester Lee, Paul Maderson, Phil Myers, Gareth Nelson, Barry OConnor, Richard O'Grady, Donn Rosen, Brad Shaffer, Peter Stevens, and E. O. Wiley for criticisms, references, and examples. W. H. Wagner, Jr., has once again pointed out my strong bias toward animals, which therefore leaves the relationship between plant ontogeny and phylogenetic inference to be explored by others.

\section{LITERATURE CITED}

Beatty, J. 1982. Classes and cladists. Syst. Zool. 31: 25-34.

BondE, N. 1976. Cladistic classification as applied to vertebrates. In Hecht, M. K., P. C. Goody, and B. M. Hecht (eds.), Major patterns in vertebrate evolution. Plenum, New York, pp. 741-804.

Bonner, J. T. 1965. Size and cycle. Princeton Univ. Press, Princeton.

Bonner, J. T. 1974. On development. Harvard Univ. Press, Cambridge.

Brady, R. H. 1979. Natural selection and the criteria by which a theory is judged. Syst. Zool. 28: $600-621$.

Brady, R. H. 1982. Theoretical issues and "pattern cladistics." Syst. Zool. 31: 286-291.

Brooks, D. R. AND E. O. Wiley. 1985. Theories and methods in different approaches to phylogenetic systematics. Cladistics 1: 1-11.

Butler, C. 1933. The effects of X-radiation on the regeneration of the forelimbs of Ambystoma larvae. J. Exp. Zool. 65: 271-315.

Caplan, A. I., And C. P. Ordahl. 1978. Irreversible gene repression model for control of development. Sci. 201: 120-201.

Chambers, R. 1844. Vestiges of the natural history of creation [1969 facsimile of 1 st ed.]. Leicester Univ. Press, Leicester.

Connelly, T. G. 1980. The influence of hormones and other substances on lens regeneration in vitro. Differentiation 16: 85-92.

Crowson, R. A. 1970. Classification and biology. Atherton, New York.

Cunha, G. R., B. Lung, And B. Reese. 1980. Glandular epithelial induction by embryonic mesenchyme in adult bladder epithelium of balb/c mice. Investigative Urology 17 : 302-304.

DANSER, B. H. 1950. A theory of systematics. Bibliogr. Biotheor. 4: 117-180.

DARWIN, C. 1859. On the origin of species. Murray, London.

DE BeER, G. 1958. Embryos and ancestors, 3rd ed. Clarendon Press, Oxford.

Donoghue, M., ANd W. Maddison. 1982. Outgroups and ontogeny-Parsimony, information and polarity assessment. Bot. Soc. Am. Misc. Publ. 162: 78.

Ehrlich, M., aNd R. Y.-H. WANG. 1981, 5-Methylcytosine in eukaryotic DNA. Sci. 212: $1350-1357$.

Eldredge, N., and J. Cracraft. 1980. Phylogenetic patterns and the evolutionary process: Method and theory in comparative biology. Columbia Univ. Press, New York.

Estabrook, G. F. 1977. Does common equal primitive? Syst. Bot. 2: 36-42.

FARRIS, J. S. 1982. Outgroups and parsimony. Syst. Zool. 31: 328-334.

FARRIS, J. S. 1983. The logical basis of phylogenetic inference. In Platnick, N. I., and V. A. Funk (eds.), Advances in cladistics, volume 2: Proceedings of the second meeting of the Willi Hennig Society. Columbia Univ. Press, New York, pp. 7-36. 
FINK, W. L. 1982. The conceptual relationship between ontogeny and phylogeny. Paleobiology 8: $254-264$.

Foster, A. S. 1949. Practical plant anatomy. Von Nostrand, New York.

GaRstang, W. 1922. The theory of recapitulation: A critical restatement of the biogenetic law. J. Linn. Soc. Zool. 35: 81-101.

Gould, S. J. 1977. Ontogeny and phylogeny. Harvard Univ. Press, Cambridge.

Grandjean, F. 1957. L'évolution selon l'age. Arch. Sci. Geneve 10: 477-526.

Grant, P. 1978. Biology of developing systems. Holt, Rinehart and Winston, New York.

HAECKEL, E. 1866. Generelle Morphologie der Organismen: Allgemeine Grundzuge der organischen Formen-Wissenschaft, mechanische begrundet durch die von Charles Darwin reformirte Descendenz-Theorie, 2 vols. Reimer, Berlin.

HaECKel, E. 1874. Anthropogenie: Keimes und Stammes-Geschichte des Menschen. Engelmann, Leipzig.

Hennig, W. 1966. Phylogenetic systematics. Univ. Illinois Press, Urbana.

Holmes, S. J. 1944. Recapitulation and its causes. Quart. Rev. Biol. 19: 319-331.

Hyman, L. H. 1959. The invertebrates: smaller coelomate groups, Chaetognatha, Hemichordata, Pogonophora, Phoronida, Ectoprocta, Brachiopoda, Sipunculida-The coelomate Bilateria, vol. 5. McGraw-Hill, New York.

Johnson, P. W., S. D. Van Gundy, and W. W. Thomson. 1970. Cuticle formation in Hemicycliophora arenaria, Aphelenchus avenae and Hirschmanniella gracilis. J. Nematology 2: 59-79.

KLuge, A. G. 1984. The relevance of parsimony to phylogenetic inference. In Duncan, T., and T. Stuessy (eds.), Cladistics: Perspectives on the reconstruction of evolutionary history. Columbia Univ. Press, New York, pp. 24-38.

Kopaska-Merkel, D. C., and R. HaAck. 1982. Herbert Spencer's theorem: A reply. Syst. Zool. 31: 95-97.

Lewontin, R. C. 1972. Testing the theory of natural selection. Nature 236: 181-182.

Løvtrup, S. 1978. On von Baerian and Haeckelian recapitulation. Syst. Zool. 27: 348-352.

Løvtrup, S. 1981. Herbert Spencer's theorem. Syst. Zool. 30: 197.

LundBerg, J. G. 1973. More on primitiveness, higher level phylogenies and ontogenetic transformations. Syst. Zool. 22: 327-329.

NaEF, A. 1931. Phylogenie der Tiere. In Baur and Hartmann (eds.), Handbuch der Vererbungswissenschaft III, 1 (Liefg. 13).

Nelson, G. 1973a. The higher-level phylogeny of vertebrates. Syst. Zool. 22: 87-91.

Nelson, G. 1973b. Negative gains and positive losses: A reply to J. G. Lundberg. Syst. Zool. 22: 330

Nelson, G. 1978. Ontogeny, phylogeny, paleontology, and the biogenetic law. Syst. Zool. 27: $324-345$.

Nelson G., and N. Platnick. 1981. Systematics and biogeography: Cladistics and vicariance. Columbia Univ. Press, New York.

Patten, B. M. 1964. Foundations of embryology, 2nd ed. McGraw-Hill, New York.

Patterson, C. 1982a. Classes and cladists or individuals and evolution. Syst. Zool. 31: 284-286.

Patterson, C. 1982b. Morphological characters and homology. In Joysey, K. A., and A. E. Friday (eds.), Problems of phylogenetic reconstruction. Academic Press, New York, pp. 21-74.

Piaget, J., And B. Inhelder. 1969. The psychology of the child. Basic Books, New York.

Platnick, N. I. 1979. Philosophy and the transformation of cladistics. Syst. Zool. 28: 537-546.

Platnick, N. I. 1982. Defining characters and evolutionary groups. Syst. Zool. 31: 282-284.

Rensch, B. 1960. Evolution above the species level. Columbia Univ. Press, New York.

ReYer, R. W. 1977. The amphibian eye: Development and regeneration. In Crescitelli, F. (ed.), Handbook of sensory physiology. Springer-Verlag, New York, pp. 309-390.

RIEPPEL, O. 1979. Ontogeny and the recognition of primitive character-states. Z. Zool. Syst. Evolut.-forsch. 17: 57-61.

Rosen, D. E. 1982. Do current theories of evolution satisfy the basic requirements of explanation? Syst. Zool. 31: 76-85.

Russell, E. S. 1916. Form and function: A contribution to the history of animal morphology. Murray, London (Univ. Chicago reprint, 1982).

Siewing, R. 1963. Discussion following Siewing's paper. In Whittington, H. B., and W. D. I. Rolfe 
(eds.), Phylogeny and evolution of Crustacea. Spec. Publ. Mus. Comp. Zool., pp. 105-110.

Sмiтh, H. M. 1960. Evolution of chordate structure. Holt, Rinehart and Winston, New York. Sober, E. 1975. Simplicity. Clarendon Press, Oxford.

Spencer, H. 1864. The principles of biology, vol. 1. Williams and Nogate, London.

Spratt, N. T. 1964. Introduction to cell differentiation. Reinhold, New York.

STEEN, T. P. 1970. Origion and differentiative capacities of cells in the blastema of the regenerating salamander limb. Am. Zool. 10: 119-132.

Stevens, P. F. 1980. Evolutionary polarity of character states. Ann. Rev. Ecol. Syst. 11: 333-358.

STRYER, L. 1981. Biochemistry, 2nd ed. Freeman, San Francisco.

Thornton, C. S. 1938. The histogenesis of muscle in the regenerating forelimb of larval Ambystoma punctatum. J. Morph. 62: 17-47.

UY, R., AND F. Wol. . 1977. Posttranslational covalent modification of proteins. Sci. 198: 890-896.

VAN DER HAMMEN, L. 1964. The relation between phylogeny and postembryonic ontogeny in actinotrichid mites. Acarologia 6: 85-90.

VAN DER HAMmen, L. 1978. The evolution of the chelicerate life-cycle. Acta Biotheor. 27: 44-60.

VAN DER HAMMEN, L. 1981. Numerical changes and evolution in actinotrichid mites (Chelicerata). Zool. Verh. Leiden 182: 3-47.

VON BAER, K. E. 1828-1837. Entwicklungsgeschichte der Thiere: Beobachtung und Reflexion. Borntrager, Konigsberg.

Voorzanger, B., and W. J. Van der Steen. 1982. New perspectives on the Biogenetic Law? Syst. Zool. 31: 202-205.

Waddington, C. H. 1966. Principles of development and differentiation. Macmillan, New York.

WATANABE, K. 1978. Individual variation in the distribution of lens potency in Wolffian lens regeneration. Development, Growth and Differentiation 20: 169-178.

Wiley, E. O. 1981. Phylogenetics: The theory and practice of phylogenetic systematics. Wiley, New York.

Woodring, J. P. 1969. Preliminary observations on moulting and limb regeneration in the mite Caloglyphus boharti. J. Insect Physiol. 15: 1719-1728. 